\title{
Análise do Funcionamento de Comunidades Terapêuticas na Perspectiva da Política Nacional Sobre Drogas
}

\section{Sarah Lima Verde da Silva}

Mestre em Planejamento em Políticas Publicas - UECE

Francisco Horacio da Silva Frota

Doutor em Sociologia pela Universidade de Salamanca

Professor do Programa de Pós-Graduação em Educação (PPGE) da UECE

\section{Maria Andrea Luz da Silva}

Mestra em Planejamento e Políticas Públicas pela Universidade Estadual do Ceará - UECE

Professora do Programa de Pós-Graduação em Educação (PPGE) da UECE

\section{Resumo}

O estudo objetivou analisar o funcionamento de Comunidades Terapêuticas na perspectiva da Política Nacional sobre Drogas. Trata-se de um estudo exploratório e descritivo com abordagem qualitativa, desenvolvido em quatro Comunidades Terapêuticas localizadas no município de Caucaia-CE, com vinte e nove sujeitos, representados pelos usuários e profissionais das instituições. Os dados foram coletados através de observação participante e entrevista semiestruturada e, posteriormente, submetidos à análise de conteúdo. Resultados denotam que o funcionamento das Comunidades Terapêuticas não atende totalmente as determinações legais quanto aos seguintes aspectos: ambiente físico, capacidade e condições de acomodação, equipe de trabalho, recursos terapêuticos e atividades ofertadas, tempo máximo de permanência do residente na instituição, objetivo do tratamento, respeito às singularidades dos residentes e articulação com dispositivos da Rede de Atenção Psicossocial. Apesar das ilegalidades e irregularidades, as Comunidades Terapêuticas permanecem acolhendo usuários de drogas e familiares que encontram dificuldades em acessar espaços formais de tratamento, fato que contribui para seu fortalecimento e expansão.

Palavras-chave: Comunidade Terapêutica; Transtornos Relacionados ao Uso de Substâncias; Políticas Públicas. 


\begin{abstract}
The study aimed to analyze the functioning of Therapeutic Communities in the perspective of the National Policy on Drugs. This is an exploratory and descriptive study with a qualitative approach, developed in four Therapeutic Communities located in the municipality of Caucaia-CE, with twenty-nine subjects, represented by users and professionals of the institutions. Data were collected through participant observation and semi-structured interview and, subsequently, submitted to content analysis. Results indicate that the functioning of the Therapeutic Communities does not fully comply with the legal requirements regarding: physical environment, capacity and accommodation conditions, work team, therapeutic resources and activities offered, maximum length of stay of the resident in the institution, treatment objective, Respect for the singularities of the residents and articulation with devices of the Network of Psychosocial Attention. Despite the illegalities and irregularities, the Therapeutic Communities continue to welcome drug users and family members who find it difficult to access formal treatment spaces, a fact that contributes to their strengthening and expansion.
\end{abstract}

Key words: Therapeutic Community; Substance Related Disorders; Public Policies. 


\section{Introdução}

Historicamente a saúde pública brasileira não se ocupou devidamente com a prevenção e tratamento de transtornos associados ao consumo de drogas. Isso produziu uma importante lacuna na política pública de saúde, deixando a questão das drogas para instituições da justiça, segurança pública, pedagogia, benemerência, associações religiosas, etc. A complexidade do problema contribuiu para relativa ausência do Estado, e possibilitou a disseminação em todo o Brasil de alternativas de atenção baseadas em práticas predominantemente psiquiátricas ou médica, ou ainda, de cunho religioso, tendo como principal objetivo, a abstinência (BRASIL, 2005).

Atualmente, o enfrentamento desta problemática constitui uma demanda mundial. De acordo com a Organização Mundial de Saúde (2001), pelo menos 10\% das populações dos centros urbanos de todo o mundo consomem de modo prejudicial substâncias psicoativas, independente de sexo, idade e nível escolar.

Sob a prerrogativa da necessidade de interligar as entidades que promovem o acolhimento de pessoas com problemas decorrentes do abuso ou dependência de substância psicoativa com a rede de cuidados, atenção, tratamento, proteção, promoção e reinserção social, a Portaria nํ 3.088, de 23 de dezembro de 2011 definiu as Comunidades Terapêuticas como um dos pontos de atenção que oferece cuidados contínuos de saúde, por até nove meses, para adultos com necessidades clínicas estáveis decorrentes do uso drogas psicoativas.

Todavia a Associação Brasileira de Saúde Mental (2015), defensora da Participação Popular nas Políticas Públicas, tem se posicionado a favor do Cumprimento das Resoluções da 14a Conferência Nacional de Saúde e da IV Conferência Nacional de Saúde Mental, sendo claramente contrária à inclusão e ao financiamento público de Comunidades Terapêuticas.

Entretanto, tais equipamentos vem sendo cada vez mais buscados por pessoas que necessitam de tratamento para a dependência química, sobretudo por aqueles que vivenciam dificuldades no acesso aos serviços de saúde ou não se identificam com seus programas de tratamento.

Em Caucaia, município cearense pertencente à região metropolitana de Fortaleza, as Comunidades Terapêuticas encontraram um terreno fértil para sua ascensão. Apesar de contar com serviços formais de atenção aos usuários de álcool e outras drogas, o município ganha destaque no estado pela quantidade de Comunidade Terapêticas em funcionamento, fato que dificulta o monitoramento por parte dos órgãos competentes e desperta para questionamentos acerca do modo como tem se efetivado ou não, como modalidade de tratamento para dependentes químicos. 
Diante do exposto, o presente estudo tenta solucionar o seguinte problema: Comunidades Terapêuticas funcionam conforme a legislação que versa sobre o tema? De modo a responder o questionamento, desenvolveu-se esse estudo com o objetivo de analisar o funcionamento de Comunidades Terapêuticas do município de Caucaia a partir do que institui a Política sobre Drogas no Brasil.

\section{Metodologia}

Trata-se de um estudo exploratório e descritivo, com abordagem predominantemente qualitativa, realizado em quatro comunidades terapêuticas localizadas no município de Caucaia - CE.

Inicialmente, foi solicitada à Vigilância Sanitária uma relação de Comunidades Terapêuticas que apresentavam condições legais de funcionamento. A relação continha um total de seis instituições, mas apenas quatro destas seguiam em funcionamento. Tentou-se contato telefônico com os representantes destas instituições, mas apenas duas sinalizaram a viabilidade da pesquisa.

No segundo momento, buscou-se o Conselho Municipal de Políticas sobre Drogas de Caucaia e o Conselho Estadual de Políticas sobre Drogas/CE que apontaram vinte e cinco Comunidades Terapêuticas funcionando irregularmente em decorrência da situação de ilegalidade. Deste total, apenas duas mantinham o telefone de contato institucional atualizado. Estas também foram incluídas na pesquisa pela facilidade de acesso e viabilidade.

Participaram da pesquisa nove profissionais que atuavam nas Comunidade Terapêuticas e dezenove usuários em tratamento, totalizando vinte e oito sujeitos. O número de participantes foi definido utilizando-se a técnica de saturação de informações.

Os critérios de inclusão para usuários das Comunidades Terapêuticas foram: ter idade mínima de dezoito anos, estar em tratamento há pelo menos três meses, apresentar condições físicas e psicológicas para participar da pesquisa e autorizar a participação através da assinatura do Termo de Consentimento Livre e Esclarecido (TCLE). Os critérios de inclusão para os profissionais foram: ter idade mínima de dezoito anos, ter tempo mínimo de serviço na Comunidade Terapêutica de três meses e autorizar a participação no estudo mediante assinatura do TCLE. 
A coleta de dados foi realizada através de duas técnicas: observação participante e entrevista semiestruturada. Durante a observação participante era preenchido um check list elaborado com base em documentos oficiais que regulamentam o funcionamento das Comunidades Terapêuticas (BRASIL, 2011a; BRASIL, 2011b). A entrevista com os participantes ocorreu por meio de um roteiro contendo questões acerca do funcionamento das Comunidades Terapêuticas. As falas dos sujeitos foram registradas em gravador digital e depois transcritas na íntegra para arquivos de computador. $\mathrm{O}$ anonimato das instituições e dos participantes foi mantido.

Após a coleta, procedeu-se à análise de conteúdo, de acordo com as etapas propostas por Bardin (2009): leitura dos documentos; destaque das ideias que mais se repetem; alocação das expressões e palavras com o mesmo sentido em uma mesma categoria; construção de categorias com base nas regras de homogeneidade, exaustividade, exclusividade, objetividade e pertinência; e término da análise ao ser identificado o ponto de saturação.

Os resultados foram confrontados com documentos oficiais que apoiam o processo de Reforma Psiquiátrica brasileiro e a literatura científica que aborda o tema em estudo.

O estudo seguiu os preceitos éticos da Resolução 466/12 do Conselho Nacional de Saúde que diz respeito às pesquisas envolvendo seres humanos (BRASIL, 2013). A pesquisa foi aprovada pelo Comitê de Ética e Pesquisa da Universidade Estadual do Ceará (UECE), conforme o Parecer 1852732.

\title{
Resultados e discussão
}

\section{Caracterização das Comunidades Terapêuticas}

Nesta primeira categoria temática realizou-se a caracterização das comunidades terapêuticas nas quais o estudo foi desenvolvido. Os dados encontram-se organizados em tabelas.

\author{
Tabela 1 - Distribuição das Comunidades Terapêuticas segundo tempo de \\ fundação, localização, mudança de endereço, natureza administrativa, \\ regularidade em relação as normas sanitárias e convênio público. \\ Fortaleza, CE. 2016.
}




\begin{tabular}{|l|l|}
\hline \multicolumn{1}{|c|}{ Variáveis } & F \\
\hline Tempo de fundação & 2 \\
5 anos & 1 \\
6 anos & 1 \\
8 anos & \\
Localização & 3 \\
Perímetro urbano & 1 \\
Perímetro rural & \\
Mudança de endereço & 1 \\
Nenhuma & 1 \\
2 vezes & 1 \\
4 vezes & 1 \\
5 vezes & \\
Natureza administrativa & 2 \\
Privada & 2 \\
Sem fins lucrativos & \\
Formação do responsável & 1 \\
Direito & 3 \\
Nenhuma & \\
Regularidade em relação às normas sanitárias & 2 \\
Regular & \\
Irregular & \\
Convênio público & \\
Sim & \\
Não & \\
\hline
\end{tabular}

De acordo com a Tabela 1, percebe-se que as comunidades terapêuticas estavam localizadas predominantemente no perímetro urbano do município de Caucaia, tinham tempo mínimo de cinco anos de fundação, eram de natureza privada e sem fins lucrativos. Três comunidades terapêuticas tinham histórico de várias mudanças de endereço desde a sua fundação, fato que poderia dificultar seu monitoramento pelos órgãos competentes. Logo, verificou-se que metade das instituições encontrava-se em situação irregularidade, e o restante regular.

Não se pode mensurar precisamente a quantidade de Comunidades Terapêuticas no Brasil. Segundo o "Observatório Crack é Possível Vencer", existem, no Brasil, 5.496 vagas em 252 nestas instituições e, até o final de 2014, a proposta era chegar a dez mil vagas. No entanto, segundo a Secretaria Nacional de Políticas sobre Drogas existiriam entre 2.503 
Comunidades Terapêuticas no país, atendendo a 60.000 pessoas por ano. Dados do Ministério da Saúde apontam que existem 2.500 Comunidades Terapêuticas que atendem a $80 \%$ dos dependentes de drogas. $O$ desencontro de informações sugere que há diversas entidades funcionando sem nenhum tipo de registro, o que traz desafios relacionados à fiscalização do cumprimento de requisitos mínimos de funcionamento (RIBEIRO; MINAYO, 2015).

\section{Tabela 2 - Distribuição das Comunidades Terapêuticas segundo público alvo, acesso aos serviços ofertados, tipo de admissão, valor da mensalidade, tempo estimado de internação e capacidade de acomodação. Fortaleza, CE. 2016.}

\begin{tabular}{|l|l|}
\hline \multicolumn{1}{|c|}{ Variáveis } & f \\
\hline Público alvo & 4 \\
Homens dependentes químicos & \\
Acesso aos serviços ofertados & 2 \\
Através da abordagem de rua da Igreja & 1 \\
Através do escritório da instituição & 1 \\
Através da SPD ou triagem na instituição & \\
Tipo de admissão & 2 \\
Voluntário & 2 \\
Voluntário, involuntário e compulsório & \\
Valor da mensalidade & 4 \\
Avaliado individualmente & \\
Tempo estimado de internação & 1 \\
6 meses & 2 \\
6 a 12 meses & 1 \\
Indeterminado & \\
Capacidade de acomodação & \\
Indeterminado & \\
20 vagas & \\
40 vagas & 1 \\
\hline
\end{tabular}

De acordo com a Tabela 2, em metade das Comunidades Terapêuticas o acesso era viabilizado por alguma Igreja. Isso demonstra o vínculo, confiança e poder entre essas instituições. Duas Comunidades Terapêuticas seguiam os preceitos legais e admitiam apenas residentes voluntários, as demais realizavam admissões de caráter involuntário e compulsório. Ressalte-se que em todas as instituições pesquisadas o público alvo era o masculino. 
Ao contrário do determinado legalmente, metade das instituições não determinava a capacidade de vagas e o tempo de internação. Nestas, seguia-se um tempo de internação determinado, segundo os entrevistados, pela "vontade de Deus". Nestas Comunidades Terapêuticas as condições do ambiente físico eram precárias, sendo os residentes acomodados, por exemplo, em varandas ou estábulos.

Nenhuma Comunidade Terapêutica adotava um valor mensal fixo a ser pago pelos internos e apenas uma tinha vagas gratuitas conveniadas com o governo estadual. Em caso de cobrança pela permanência do residente na comunidade terapêutica, a mesma era realizada com base em um estudo das condições financeiras da família do residente, podendo o valor mensal variar de acordo com a realidade de cada sujeito.

Tabela 3 - Distribuição das Comunidades Terapêuticas segundo formação do responsável, equipe de trabalho, visita familiar na instituição e atividades desenvolvidas rotineiramente. Fortaleza, CE. 2016.

\begin{tabular}{|l|c|}
\hline \multicolumn{1}{|c|}{ Variáveis } & f \\
\hline Equipe de trabalho & 2 \\
Monitores & 2 \\
Psicólogo, Educador físico, Técnico de enfermagem, conselheiros e & \\
monitores & \\
Visita familiar na instituição & 1 \\
A qualquer momento & 1 \\
Após 15 dias de admissão & 1 \\
Após 30 dias de admissão & 1 \\
Visita assistida após 30 dias de admissão & \\
Atividades desenvolvidas rotineiramente & 4 \\
Laborterapia & 3 \\
Atividades de cunho espiritual/religioso & 3 \\
Atividades esportivas & 2 \\
Atividade grupal baseada nos doze passos de grupos de autoajuda & 1 \\
Curso profissionalizante & 1 \\
Atendimento familiar & \\
\hline
\end{tabular}

De acordo com a Tabela 3, duas comunidades terapêuticas possuíam apenas residentes monitores na equipe de trabalho, as demais tinham contavam com psicólogo, educador físico, técnico de enfermagem, conselheiros e monitores. O fato de haverem técnicos de enfermagem trabalhando sem a presença/supervisão de um enfermeiro contraria o que prevê o Conselho Federal de Enfermagem. 
Comunidades Terapêuticas não se configuram como serviços de saúde. O principal instrumento terapêutico utilizado para o tratamento das pessoas com transtornos decorrentes de uso, abuso ou dependência de substâncias psicoativas deve ser a convivência entre os pares. Assim, não há exigência quanto à composição de uma equipe multidisciplinar, apenas de um responsável técnico de nível superior (em qualquer área). Por outro lado, a legislação destaca a necessidade de manter uma articulação com a Rede de Atenção Psicossocial quando houver necessidade de suporte psicossocial (BRASIL, 2011a).

No tocante às visitas de familiares, três comunidades terapêuticas estipulavam um tempo mínimo para que os residentes pudessem recebê-las e, ainda assim, as mesmas só eram permitidas após parecer favorável da instituição. Partilhava-se a crença de que o encontro com os familiares sem o devido parecer da instituição pudesse agravar conflitos. Apenas uma instituição permitia o acesso livre dos familiares diariamente.

As Comunidades Terapêuticas tem a obrigação de garantir a participação da família ou de pessoa indicada pelo acolhido no processo de acolhimento, bem como nas ações de preparação para a reinserção social. Porém, os documentos oficiais não detalham como deve ocorrer essa participação, bem como o tempo para tal, ficando a critério da instituição conduzi-la (BRASIL, 2015).

Em relação as atividades desenvolvidas nas comunidades terapêuticas, destacaram-se: laborterapia (organização e limpeza do ambiente, preparo de alimentação), atividades de cunho religioso (louvores, leitura da Bíblia, culto, adoração, vigília, jejum, oração), atividades esportivas e recreativas (futebol, banho de piscina), grupos baseados nos Doze Passos adotados em grupos de autoajuda e visitas de familiares. Foi mencionada a "sonoterapia" como atividade ofertada aos residentes, no entanto, tratava-se de um momento de sono/repouso sem cunho terapêutico ou cuidado profissional.

Desde as primeiras Comunidades Terapêuticas os residentes assumiam completamente a responsabilidade pela administração da vida diária e da operação das instalações que ocupavam. Hoje, em algumas dessas instituições, subsídios do governo suplementados por fundos privados auxiliam nas despesas, não obstante, o trabalho segue sendo visto como necessário em termos físicos, psicológicos e sociais. Embora ainda fundamentada na necessidade, o trabalho é defendido com profunda significação social e psicológica no processo de recuperação pelos seus interessados, que organiza inclusive as atividades veladamente baseado em uma lógica hierárquica e de poder (DE LEON, 2003).

Segundo Foucault (2000), as práticas laborterápicas baseiam-se na produção de corpos dóceis, no treinamento de hábitos de trabalho, de comportamentos considerados adequados, limitados e subservientes, nada questionadores. De acordo com Kinker (2014), a Comunidade Terapêutica, que surgiu como um dispositivo de superação do modelo manicomial, pode acabar retomando velhos paradigmas sob novas justificativas.

À exceção de uma Comunidade Terapêutica que lidava com a espiritualidade sem 
conotação diretiva religiosa, as demais trabalhavam rotineiramente atividades de cunho religioso, claramente tendenciosas para as práticas evangélicas protestantes.

A predominância de práticas evangélicas no contexto em estudo decorre de um cenário sócio-político anterior de surgimento desses equipamentos no Brasil, definido pelo aumento do uso de drogas na população, escassez de programas de tratamento específico e por uma política pública para usuários de drogas ainda sem definição clara. Logo, entende-se hoje o motivo pelo qual muitas Comunidades Terapêuticas, também cunhadas como "Centros de Recuperação", são financiadas ou cofinanciadas por entidades religiosas e pelo Estado, tendo como projeto terapêutico o tratamento religioso. Este tipo de tratamento tem como objetivo substituir ou incrementar outras formas de cuidado, como a medicamentosa (RIBEIRO; MINAYO, 2015).

Os achados expostos nessa primeira categoria permitem caracterizar as Comunidade Terapêuticas como espaços que, apesar das irregularidades observadas com relação a alguns requisitos previstos por lei, acolhem demanda significativa de dependentes químicos e ofertam um tratamento que podem estar na contramão dos ideais do Movimento de Reforma Psiquiátrica brasileiro e da Política Nacional sobre Drogas.

\section{Semelhanças no tratamento ofertado pelas comunida- des terapêuticas}

A presente categoria foi elaborada de modo a apresentar e discutir as semelhanças encontradas no tratamento ofertado pelas Comunidades Terapêuticas, a saber: a abstinência como objetivo, a abordagem de cunho espiritual e religiosa, a participação familiar e a frágil articulação com a RAPS.

O tratamento nas Comunidade Terapêutica ocorria por meio de internação de longa duração, em regime residencial e tinha a abstinência como foco. As falas a seguir ilustram os achados:

"Só de eu estar aqui me tratando, não estou usando droga, não estou mais bebendo nem nada. Eu me sinto bem só em estar aqui e não estar lá fora usando essas coisas que não prestam." (Entrevistado 23)

"Eu preciso para que eu me mantenha limpo" (Entrevistado 29)

Diferente da proposta de tratamento de longo período, o Movimento de Reforma Psiquiátrica brasileiro sugere que o tratamento em regime integral seja uma alternativa apenas quando os recursos extra-hospitalares mostrarem-se insuficientes. É direito da 


\section{Análise do funcionamento de comunidades terapêuticas \\ na perspectiva da Política Nacional Sobre Drogas}

pessoa com transtorno mental ser tratada preferencialmente em serviços de base comunitária. Nesse sentido, reforça-se a intenção de ruptura com o modelo hospitalocêntrico, de modo a evitar a institucionalização, marcadamente presente na história de tratamento em saúde mental (BRASIL, 2001b).

A Resolução 01/2015 do CONAD estabelece o período máximo de 1 ano para tratamento em Comunidade Terapêutica. Já a Resolução 29 da ANVISA de 2011 institui que durante o período de permanência na Comunidade Terapêutica deve ser assegurado ao residente cuidado com o bem estar físico e psíquico da pessoa, proporcionando um ambiente livre de substâncias psicoativas e violência (BRASIL, 2011b; BRASIL, 2015).

A Política Nacional sobre Drogas adota o método da Redução de Danos em suas abordagens, a qual não exclui a abstinência, tampouco a coloca como foco do tratamento. A redução de danos não se opõe ao uso de estratégias clínicas que pressupõem a abstinência, pois reconhece sua relevância e necessidade para muitos, porém não concorda com o posicionamento de alguns dispositivos de atenção em saúde que defendem a abstinência como único objetivo do tratamento, compreendendo apenas esse recurso como uma possibilidade entre as várias existentes (CRUZ, 2006).

Outro ponto em comum nos relatos dos participantes foi a ênfase na abordagem espiritual/religiosa durante o tratamento:

"Nós trabalhamos aqui com espiritualidade, em nenhum momento é citado religião. É justamente esse embasamento que nós temos dos Doze Passos (de Alcoólicos Anônimos), que ela é uma terapia bem eclética, que pessoas que chegam a nós eles vêm de vários direcionamentos religiosos. Nós somos muito cuidadosos nós trabalhamos uma coisa que se chama espiritualidade. Independente de qual religião ele vai, ele mesmo fazer o seu trabalho religioso, mas nós trabalhamos essa parte da espiritualidade: faça o bem, empregue o bem, não faça com o outro aquilo que não gostaria que seja feito consigo". (Entrevistado 2)

"A espiritualidade deles é muito bem trabalhada, aqui a gente não rege religiões, cada um tem a sua aqui não tem nada a ver com crente, católico, a religião aqui a gente aceita todas as religiões, mas no caso da espiritualidade que tem até uma reunião para isso eles mesmos fazem a rodinha de conversas, debate diz como é que tá o que é que espera no poder superior, falam muito de Deus, a maioria deles falam de Deus, então eles entram em si no diálogo agradável, assim tirando as suas próprias dúvidas espirituais" (Entrevistado 27)

A espiritualidade é uma característica única e individual que pode ou não incluir a crença em um "Deus", sendo aquela responsável pela ligação do "eu" com o Universo e com os outros, a qual também está além da religiosidade e da religião. Já a religiosidade é definida como a crença e a prática dos fundamentos propostos por uma religião. Sobre as interfaces entre o consumo de drogas, espiritualidade e religiosidade, alguns estudos destacam a prática religiosa como um fator de proteção para o uso de drogas. A prática de uma 
religião pode retardar o primeiro uso do álcool e influenciar em uma menor frequência posterior do seu consumo (SANCHEZ; NAPPO, 2007)

De acordo com alguns relatos dos participantes, ficou evidente que o referido trabaIho dito espiritual era tendencioso para a religião à qual os responsáveis pela comunidade terapêutica compartilhavam:

"Eu como dependente químico para eu parar, para eu ter uma nova maneira de viver, precisa também saber que existe um poder maior do que eu, que existe Deus, que existe uma forma de viver pro lado da espiritualidade. A gente tem parceria com a igreja evangélica onde pastores vem trazendo a mensagem da Bíblia, mensagem de fé, força e esperança” (Entrevistado 3)

"Quem vem para cá sempre foi católico, é ex-macumbeiro ou essas coisas. Quando o cara sai da religião dele e entra nesse mundo das drogas, ele perde tudo, não sabe mais o que é religião, não quer mais saber de nada. Tem umas pessoas aqui que ainda hoje tem o símbolo de cinco pontos do satanismo na mão, candomblecista mesmo e hoje é liberto por Deus. Quando ele chega aqui, a gente pergunta: "Você quer aceitar Jesus novamente? Você quer ser crente, você quer servir à Deus?” Se ele disser que não quer a gente também não vai botar ele para fora não, ele fica lá...Mas se ele for um candomblecista, um macumbeiro, essas coisas, a casa não aceita... aqui não é só uma clínica de recuperação, é uma casa de Deus... aqui dentro, são induzidos ser cristão, se ele não quer também não tem problema, ele não vai seguir eu não boto ele para fora, só que as outras atividades dele como macumba, como candomblé, como espírita... eles não tem força nem pra ficar em pé, quanto mais pra fazer as coisas sozinho. Ai tem que ser o que os outros estão fazendo mesmo que ele faz, ai ele vai ter que fazer o que os outros fazem" (Entrevistado 4)

Apesar da relevância da espiritualidade e religiosidade no tratamento de pessoas com dependência química, o modo como tais abordagens é realizado pode repercutir de várias formas na vida do sujeito, inclusive de maneira negativa, desrespeitosa ou mesmo criminosa. As falas destacadas demonstram preconceito em relação a algumas crenças e religiões, negação de algumas práticas religiosas e espirituais ou mesmo a não aceitação de determinadas opções religiosas.

Tanto a Declaração Universal dos Direitos Humanos, como a Constituição Federal de 1988 definem a liberdade de religião, prescrevendo que o Brasil é um país laico, portanto deve prevalecer a separação entre Estado e Igreja, o que não se observa absolutamente, a exemplo dos feriados nacionais religiosos por exemplo. Nesse sentido, inconstitucionalidades como o convênio do estado com comunidades terapêuticas religiosas ainda ocorrem (BRASIL, 2000).

Todos os participantes ressaltaram a importância da participação da família no tratamento, de modo a reforçar o apoio ao dependente químico mas, também, de modo a 


\section{Análise do funcionamento de comunidades terapêuticas \\ na perspectiva da Política Nacional Sobre Drogas}

tentar lidar com o sofrimento e adoecimento que a dependência química traz aos familiares. Em alguns relatos ficou evidente que a Comunidade Terapêutica apenas permite a visita familiar, em outros percebeu-se a existência de acompanhamento profissional para familiares dos residentes:

"Em relação ao contato familiar é estabelecido a partir de trinta dias a primeira visita, dependendo da relação entre o residente e o familiar. O que acontece na dependência química é uma relação de co-dependência em que, muitas vezes, o próprio familiar atrapalha o tratamento desse indivíduo, que já vem dessa carência da relação junto de casa. Então, nós estudamos como vai ser o primeiro contato saudável, nós instruímos tanto familiar, como preparamos o residente, para eles se encontrarem de uma forma em que o residente não vá usar mais uma vez a situação do coitadinho." (Entrevistado 2)

"Primeiramente, a gente tem a visita assistida, que é uma visita individual, é a primeira visita após trinta dias do ingresso do aluno. Primeiro vem a família, a família é comunicada, e aí essa visita realizada pelo profissional da instituição, psicólogo e o terapeuta que acompanha esse aluno diariamente, o terapeuta do aluno, e eles vão falar para a família como que está o desenvolvimento do aluno, o que é que está acontecendo, vai atender também a família, saber como que a família está, o que é que está acontecendo com a família." (Entrevistado 3)

"Nós temos três visitas no mês, a gente tem um atendimento que é só da família. Nesse atendimento a gente vai mostrar os pontos, muitos deles são co-dependentes da doença. Tem a visita também que é assistida com uma psicóloga." (Entrevistada 28)

"A co-dependência é uma realidade nos lares que tem dependente químico. A família depende daquele adicto para se sentir bem e por conta disso acaba oprimindo e conduzindo a situação de forma errada. Nós valorizamos muito o atendimento com as famílias, a presença da família nas reuniões. É imprescindível para o crescimento do adicto." (Entrevistado 29)

Ressalte-se a importância do papel da família como principal fonte de apoio e sustentação no tratamento, essencial para manter o vínculo social do usuário de drogas. A família tem papel central e deve ser considerada como um apoio, ainda que apresente sinais de adoecimento decorrente de suas experiências traumáticas e vivências cotidianas impostas pelo usuário de drogas. Enquanto co-dependente, é necessário que a família tenha um acompanhamento terapêutico para aprender a lidar com estas situações e poder atuar junto a seu familiar usuário de drogas, de forma mais instrumentalizada, não permitindo que ele interfira em suas expectativas e projetos de vida (ALVAREZ et al, 2012)

O pensamento ecológico defende que as pessoas estão interligadas e interconectados, por conseguinte, a mudança em um indivíduo provoca reverberação em todo o sistema. Logo, a necessidade de submersão na rede de relações do indivíduo, onde a família de um modo geral surge a priori, apontam fatores de risco e proteção que servem para subsidiar 
ações efetivas de caráter preventivo ou de intervenção. (SOUSA; KANTORSKI; MIELKE, 2006).

As falas dos entrevistados denotam, ainda, fragilidades na articulação das Comunidades Terapêuticas com os demais serviços de atenção e apoio que compõem a RAPS. Em geral, quando a busca por atendimento nesses serviços ocorria era com o intuito de receber prescrição medicamentosa ou referência para internação hospitalar. Tais achados denotam um reforço à cultura de medicalização e segregação do usuário de drogas:

"Bom esses outros serviços eles de fato só estão no papel. Quando a gente vai por tudo isso em prática existe sempre uma burocracia. Quando a gente precisa de um atendimento dentro de uma UPA, de um CAPS a gente nunca é atendido. Outro desafio: a questão da ida em hospitais. Era para ter uma rede que atendesse bem, com flexibilidade. Se for no caso de surto por conta da droga, a gente tenta com a família e o Hospital Mental uma vaga." (Entrevistado 28)

"Costumamos utilizar sim, essa parceria é uma parceria necessária. O CAPS é o nosso apoio psiquiátrico e também é de onde nós recebemos orientações acerca de alguns assuntos relacionados à psicologia, horários de medicamentos, o efeito de alguns medicamentos. Nesse ponto aí é que eu vejo a importância do atendimento no CAPS, eles vão proporcionar ao residente através da farmacologia a medicação correta, para que ele possa controlar os seus impulsos relacionados à abstinência." (Entrevistado 29)

A RAPS integra o Sistema Único de Saúde (SUS) e busca consolidar um modelo de atenção aberto e de base comunitária. São tidos como componentes da RAPS: atenção básica, atenção psicossocial, atenção de urgência e emergência, atenção residencial de caráter transitório, atenção hospitalar, estratégias de desinstitucionalização e estratégias de reabilitação psicossocial (BRASIL, 2011c).

Comunidades Terapêuticas enquanto ponto de atenção da RAPS deveriam estar em articulação aos demais equipamentos, haja vista a complexidade que envolve o fenômeno do uso de drogas, o que não se evidencia na fala dos participantes. Em contrapartida, o que fica notório é uma tímida aproximação destas instituições com os CAPS, tomando simplista o objetivo destes últimos, reduzindo-os a mero dispensadores de receituários e medicamentos, reforçando a perspectiva histórica de serviços de saúde centrados no modelo biomédico e na cultura de medicalização da loucura.

Conclui-se que o funcionamento das Comunidades Terapêuticas não atendia totalmente as determinações legais no que diz respeito a alguns aspectos como: ambiente físico, capacidade e condições de acomodação, equipe de trabalho, recursos terapêuticos 
e atividades ofertadas, tempo máximo de permanência do residente na instituição, objetivo do tratamento, respeito às singularidades dos residentes e articulação com dispositivos da Rede de Atenção Psicossocial.

Apesar das ilegalidades e irregularidades, as Comunidades Terapêuticas desempenham papel importante no acolhimento de usuários de drogas e familiares que, por vezes, encontram dificuldades em acessar espaços formais de tratamento, fato que contribui para seu fortalecimento e expansão.

\section{Considerações Finais}

As Comunidades Terapêuticas podem oferecer uma importante contribuição para a compreensão e tratamento de uma parcela de pessoas com problemas relacionados ao uso de substâncias psicoativas. Para tanto, tais instituições dependem de instalações adequadas às necessidades dos indivíduos atendidos e equipes multidisciplinares integradas, que possam oferecer atenção em diferentes níveis, a partir de um modelo teórico coeso e com implicações práticas claramente definidas.

Com base nos resultados da pesquisa, pode-se afirmar que o funcionamento das Comunidades Terapêuticas não contemplava totalmente o que preconiza a Política Nacional Sobre Drogas e os ideais da Reforma Psiquiátrica brasileira. Mesmo assim, a aceitação e o acolhimento encontrados em Comunidades Terapêuticas favorece a identificação dos sujeitos com o tratamento proposto, que tem como objetivo a abstinência.

Apesar das irregularidades observadas nas Comunidades Terapêuticas estudadas, estas podem atender as expectativas de muitas pessoas que dela usufruem. Logo, acredita-se que se houvesse um maior rigor na fiscalização, monitoramento sistemático, supervisão com o intuito de ajustar as irregularidades e o incentivo do governo para a construção de Comunidades Terapêuticas públicas, estas poderiam ter grande potencial para efetivamente representar um modelo de tratamento substitutivo à lógica manicomial. Enquanto isso não se concretiza, fortes semelhanças podem ser identificadas entre o modelo de tratamento ofertado por Comunidades Terapêuticas e o manicomial pregresso. 


\section{Referências}

ABRASME. Carta manifesto acerca do processo de financiamento público das Comunidades Terapêuticas e outras entidades. 06/03/2015. Disponível em http://antimanicomialsp. wordpress.com/tag/associacao-brasileira-de-saude-mental-abrasme/htm. Acesso em 28 abr 2016.

ALVAREZ, SQ. et al. Grupo de apoio/suporte como estratégia de cuidado: importância para familiares de usuários de drogas. Rev. Gaúcha de Enfermagem, Porto Alegre (RS) 2012 jun;33(2):102-108.

BARDIN, L. Análise de conteúdo. Lisboa: Edições Setenta, 2009.

BRASIL. Ministério da Justiça. Conselho Nacional de política sobre Drogas. Regulamenta no âmbito do SISNAD as entidades caracterizadas como Comunidades Terapêuticas. Resolução 01/2015. Brasília, 2015. Disponível em: http://www.cruzazul.org.br/uploads/Resolucao-N-1-2015-CONAD-Regulamentacao-CTs.pdf

Ministério da Saúde. Conselho Nacional de Saúde. Normas de pesquisa envolvendo seres humanos. Res. CNS 466/12. Brasília, 2013. Disponível em: http://conselho. saude.gov.br/web_comissoes/conep/index.html

Agência Nacional de Vigilância Sanitária - ANVISA. Resolução no. 29, de 30 de junho de 2011. Diário Oficial da União: poder executivo. Brasília, $2011 a$.

Ministério da Saúde. Portaria n 3.088, de 23 de dezembro de 2011. Diário Oficial da União: poder executivo. Brasília, 2011c.

Reforma Psiquiátrica e política de Saúde Mental no Brasil. Conferência Regional de Reforma dos Serviços de Saúde Mental: 15 anos depois de Caracas. Brasília, 2005. 
Ministério da Saúde. Lei 10.216, de 06 de abril de 2001. Diário Oficial da União: poder executivo. Brasília, 2001b.

Constituição (1988). Constituição da República Federativa do Brasil. Organização de Alexandre de Moraes. 16. Ed. São Paulo: Atlas, 2000.

CRUZ, M. S. Considerações sobre possíveis razões para a resistência às estratégias de redução de danos. In: CIRINO, O.; MEDEIROS, R. (Orgs.). Álcool e outras drogas: escolhas, impasses e saídas possíveis. Belo Horizonte: Autêntica, 2006.

DE LEON, George. A Comunidade Terapêutica: teoria, modelo e método. Edições Loyola: São Paulo, 1 edição, 2003.

FOUCAULT, Michel. Vigiar e punir. Tradução de Raquel Ramalhete. 23. ed. Petrópolis: Vozes, 2000.

KINKER, Fernando Sfair. Enfrentamentos e construção de projetos de trabalho para a superação da laborterapia. Caderno de Terapia Ocupacional, São Paulo,v.22. n 1, p. 49- 61, 2014.

ORGANIZAÇÃO MUNDIAL DE SAÚDE. Relatório sobre a Saúde no Mundo 2001 - Saúde Mental: Nova Concepção, Nova Esperança. OMS, Genebra, 2001.

RIBEIRO, Fernanda Mendes Lages; MINAYO, Maria Cecília de Souza. As Comunidades Terapêuticas religiosas na recuperação de dependentes de drogas: o caso de Manguinhos, RJ, Brasil. Interface (Botucatu), Botucatu, v.19, n. 54, p. 515-526, Set. 2015.

SANCHEZ, Zila Van Der Meer; NAPPO, Solgande Aparecida. Religiosity, spirituality and psychotropic drug use. Archives of Clinical Psychiatry (São Paulo), 2007, vol.34, n. , ISSN 0101-6083. 
SOUZA, Jacqueline de; KANTORSKI, Luciane Prado; MIELKE, Fernanda Barreto. Vínculos e redes sociais de indivíduos dependentes de substâncias psicoativas sob tratamento em CAPS AD. SMAD, Rev. Eletrônica Saúde Mental Álcool e Drogas. (Ed. port.), Ribeirão Preto, v. 2, n. 1, fev. 2006. Disponível em: <http://pepsic.bvsalud.org/scielo.php?script=sci_arttext\&pid=S1806-69762006000100003\&lng=pt\&nrm=iso>. acessos em 29 dez. 2016. 